\title{
Diagnostic accuracy of Somaticell, California Mastitis Test, and microbiological examination of composite milk to detect Streptococcus agalactiae intramammary infections
}

\author{
R. S. Rossi, ${ }^{*}$ A. F. Amarante, ${ }^{*}$ L. B. N. Correia, ${ }^{*}$ S. T. Guerra, ${ }^{*}$ D. B. Nobrega,† G. S. Latosinski, ${ }^{\text {B } B . ~ F . ~ R o s s i, \ddagger ~}$ \\ V. L. M. Rall, $\ddagger$ and J. C. F. Pantoja*1 \\ *Department of Veterinary Hygiene and Public Health, School of Veterinary Medicine and Animal Science, Sao Paulo State University (UNESP), \\ Botucatu, SP, Brazil, 18618-681 \\ †Department of Production Animal Health, Faculty of Veterinary Medicine, University of Calgary, Calgary, AB, Canada, T2N 1N4 \\ ‡Department of Microbiology and Immunology, Institute of Biosciences, Sao Paulo State University (UNESP), Botucatu, SP, Brazil, 18618-689
}

\begin{abstract}
The objectives of this study were to estimate the accuracy of Somaticell (Idexx Laboratories Inc., Westbrook, ME), California Mastitis Test (CMT), and microbiological examination of composite milk (MEC) to diagnose Streptococcus agalactiae intramammary infections (IMI), and to assess the agreement between Somaticell and CMT to detect these infections. A secondary objective was to estimate quarter- and cow-level prevalence of $S$. agalactiae IMI in the herds included in the study. Seven farms were included in the study. The CMT was performed and aseptic milk samples were collected from all quarters of all lactating cows. Composite milk samples were produced in the laboratory by mixing milk from all quarters of each sampled cow. The Somaticell test was performed on a subset of $S$. agalactiae-positive $(\mathrm{n}=167)$ and $S$. agalactiae-negative $(\mathrm{n}=152)$ quarter milk samples. Microbiological examination of quarter milk samples (MEQ) was considered the reference test for diagnosing $S$. agalactiae IMI. The accuracy of all tests at various thresholds was estimated using Bayesian latent class models. Apparent prevalence of $S$. agalactiae IMI was $15.8 \%(\mathrm{n}=184 / 1,164)$ at the quarter level (based on MEQ) and 28.5\% $(\mathrm{n}=83 / 291)$ at the cow level (based on MEC). True prevalence, as determined by Bayesian models, was 13.0\% [95\% credible interval (CR): 6.4-24.4\%] at the quarter level, and $25.6 \%$ (95\% CR: 15.3-39.5\%) at the cow level. At the cow level $(\mathrm{n}=285)$, sensitivity and specificity of MEC were 95.6 and $99.5 \%$, respectively. The accuracy of Somaticell ( $\mathrm{n}=319$ quarters) to identify S. agalactiaeinfected quarters was $75.4,86.4,88.9,89.4$, and $91.0 \%$
\end{abstract}

Received March 16, 2018.

Accepted June 8, 2018.

${ }^{1}$ Corresponding author: pantoja@fmvz.unesp.br at thresholds of 98,000,147,000, 205,000, 244,000, and 282,000 cells $/ \mathrm{mL}$, respectively. The accuracy of CMT was $87.6,90.7,90.8$, and $87.4 \%$ at thresholds of trace, 1,2 , and 3 , respectively. The areas under the receiver operating characteristic curve for Somaticell and CMT were $94.5 \%$ (95\% confidence interval: $91.8-97.2 \%)$ and $92.0 \%$ (88.6-95.4\%), respectively. At the tested thresholds, the sensitivity of Somaticell ranged from 94.9 to $99.5 \%$ to detect $S$. agalactiae IMI, and specificity ranged from 48.1 to $87.1 \%$. The sensitivity of Somaticell at the lowest threshold $(69,000$ cells/mL; sensitivity $=99.9 \%$; 95\% CR: $98.2-100 \%)$ was higher than that of CMT at any tested threshold. Results of this study could be used at the farm level to reduce the use of antimicrobials and reach specific goals in $S$. agalactiae eradication programs.

Key words: milk quality, subclinical mastitis, diagnostic test, Streptococcus agalactiae

\section{INTRODUCTION}

Streptococcus agalactiae remains one of the most prevalent contagious pathogens in many dairy regions worldwide. Prevalences of $60 \%$ at the herd level and between 7 and $35 \%$ at the cow level have been reported in countries such as Brazil (Brito et al., 1999), China (Yang et al., 2013), Thailand (Leelahapongsathon et al., 2014), and Colombia (Ramírez et al., 2014; Reyes et al., 2015). In Denmark, a possible reemergence of this pathogen at the herd level was reported by Katholm et al. (2012).

Intramammary infections caused by $S$. agalactiae are associated with high SCC (geometric mean of 1,129,000 cells/mL at the quarter level; Djabri et al., 2002); decrease in milk production (1.6 to $4.5 \mathrm{~kg} /$ cow per day; Natzke et al., 1972; Wilson et al., 1997); and recurrent episodes of clinical mastitis (Leelahapongsathon et al., 2014). Herds infected with S. agalactiae usually 
produce bulk milk with high somatic cell and total bacteria counts (Hogan et al., 1986). Infected cows can shed up to $10^{7}$ bacteria/mL of milk (Guterbock and Blackmer, 1984).

Streptococcus agalactiae has been eradicated from developed dairy regions, by means of control programs consisting of systematic identification and treatment of infected animals ("blitz therapy"; Keefe, 1997). As part of such programs, microbiological examination of composite milk samples (MEC; a mixture of milk from all quarters of a cow) has been used as a screening strategy to identify infected animals (Reyes et al., 2015). Sensitivity and specificity of MEC were reported to be 96.5 and $100 \%$, respectively, compared with microbiological examination of quarter milk samples (MEQ; Dinsmore et al., 1991). Furthermore, no differences were noted in $S$. agalactiae recovery when a larger volume of inoculum and enhanced culture techniques, such as preincubation, were used (Dinsmore et al., 1992).

Different treatment strategies have been used to eradicate $S$. agalactiae from dairy herds. Traditionally, all quarters of all cows from which $S$. agalactiae is isolated from composite milk samples are treated with antimicrobials, regardless of the number of infected quarters (Erskine and Eberhart, 1990; Reyes et al., 2015). These strategies result in great antimicrobial waste and increased costs due to unnecessary treatment of uninfected quarters. Moreover, pressure to reduce antimicrobial use in livestock animals has increased in the last decades (European Medicines Agency, 2014).

Currently, the strategy of treating all quarters of cows previously diagnosed with $S$. agalactiae with MEC faces resistance by farmers due to the unnecessary costs of treating uninfected quarters. Identification of truly infected quarters before treatment by means of a screening test could substantially reduce treatment costs, prevent unnecessary exposure of healthy quarters to antimicrobials, and decrease the risk of bulk milk contamination with antimicrobial residues.

An alternative to identify $S$. agalactiae-infected quarters of MEC-positive cows is the California Mastitis Test (CMT). Nonetheless, the sensitivity of the CMT to detect infected quarters can result in up to $20 \%$ false-negative results (Dingwell et al., 2003). Failure to detect infected quarters is a problem in eradication programs because maintenance of reservoirs can lead to new infections and reinfection of treated and cured quarters. Somaticell (Idexx Laboratories Inc., Westbrook, ME) is a cow-side test that could be an alternative to CMT. The test is a modification of the Wisconsin Mastitis Test (Thompson and Postle, 1964) and estimates the concentration of somatic cells in milk by a chemical reaction that changes the viscosity of the solution (milk and reagent). Somaticell has been previously validated, showing strong agreement $(r=0.92)$ with SCC measured by flow cytometry (Rodrigues et al., 2009).

Both Somaticell and CMT are tests that can be easily performed in dairy herds. Assessment of both tests at different thresholds would be valuable for consultants and dairy producers to identify thresholds that would maximize the probability of detecting $S$. agalactiaeinfected quarters while ensuring that the number of unnecessary treatments is minimized. The objectives of this study were to (1) estimate the accuracy of MEC to detect cows infected with $S$. agalactiae, (2) estimate accuracy parameters of Somaticell and CMT (with focus on sensitivity) to detect $S$. agalactiae-infected quarters of MEC-positive cows, and (3) assess the agreement between Somaticell and CMT to detect these infections. A secondary objective was to estimate quarter- and cow-level prevalence of $S$. agalactiae IMI in the herds included in the study.

\section{MATERIALS AND METHODS}

This study was approved by the Sao Paulo State University (UNESP) Ethics Committee for Animal Use (protocol 07/2015). This article was prepared according to the STARD statement guidelines for reporting of diagnostic accuracy studies (Bossuyt et al., 2015).

\section{Selection and Characteristics of Herds and Cows}

Herds were eligible for enrollment into the study if they had bulk tank milk SCC >700,000 cells/mL (Erskine and Eberhart, 1990) on the last available official test day, had S. agalactiae isolated from bulk tank milk, were composed of at least 20 lactating cows (mostly Holsteins or Holstein-crossbreds), milked cows using milking machines, and offered voluntary cooperation with the study. Cows were eligible for enrollment if they were not showing any sign of other disease and were not being treated with antimicrobials for any reason.

A convenience sample of 7 dairy farms located in Sao Paulo and Minas Gerais states, Brazil, and that met the inclusion criteria, was used for the study. The study was conducted between February and October 2016. Cows were milked in pit parlors $(\mathrm{n}=4)$ or stanchion barns ( $\mathrm{n}=3$ farms). Herd size ranged from 22 to 77 lactating Holsteins or Holstein-crossbred cows. Cows were milked twice a day and kept in semi-confinement systems. Median daily milk yield was $18 \mathrm{~kg} / \mathrm{cow}$ (1st quartile $=13 \mathrm{~kg} / \mathrm{cow}$ and $3 \mathrm{rd}$ quartile $=25 \mathrm{~kg} / \mathrm{cow}$ ). 


\section{Sampling Strategy}

Farms were initially visited to explain the study protocol and obtain informed consent. After examining the first streams of milk for detection of clinical mastitis, use of predipping, and drying of teats, CMT was performed on all quarters of all lactating cows. Results were recorded as 0 (negative), trace (slight reaction), 1 (mild reaction), 2 (moderate reaction), or 3 (strong reaction). Subsequently, teat ends were scrubbed with a gauze pad soaked with $70 \%$ alcohol and milk samples $(15 \mathrm{~mL})$ were aseptically collected from all quarters tested with CMT.

Upon collection, samples were identified and maintained refrigerated until arrival at UNESP's Mastitis Research and Diagnosis Laboratory. Milk was cultured on the same day, within $24 \mathrm{~h}$ of collection.

\section{Microbiological Examination of Milk}

Milk samples were cultured according to the procedures of the National Mastitis Council (NMC, 1999). Ten microliters of milk was streaked onto a quadrant of a blood agar plate and incubated at $36^{\circ} \mathrm{C}$. Samples were read at 24, 48, and $72 \mathrm{~h}$. A positive culture was defined as the presence of pure growth of $\geq 1$ similar colonies on the plate. Samples were considered contaminated when there were $\geq 3$ types of colonies on the plate. Diagnosis of $S$. agalactiae was performed based on phenotypic (Markey et al., 2013) and genotypic methods. Isolates were diagnosed as $S$. agalactiae when they were gram-positive cocci, catalase-negative, esculin- and bile esculin-negative, and positive for the Christie, Atkins, Munch-Petersen (CAMP) test. All isolates were further submitted to PCR, as described by Chen et al. (2012), to confirm the diagnosis.

Composite milk samples were produced in the laboratory by mixing $2 \mathrm{~mL}$ of milk from each quarter sample of a cow in a $15-\mathrm{mL}$ sterile vial. Subsequently, $10 \mu \mathrm{L}$ of the composite milk was inoculated onto a quadrant of a blood agar plate and incubated for $72 \mathrm{~h}$ at $36^{\circ} \mathrm{C}$, as previously described. When growth of streptococci exhibiting different types of hemolysis $(\alpha, \beta$, or $\gamma)$ was observed within the same quadrant, 1 colony of each hemolysis type was submitted to the aforementioned tests. When only 1 pattern of hemolysis was observed, the quadrant was divided into 3 equal areas and 1 colony from each area was selected. Microbiological examination of composite and quarter milk samples was performed blindly, so that the investigators could not know the results of MEQ before reading the results of MEC.

Somaticell (Madasa) was used to estimate SCC on most (n $=167$ of 184) S. agalactiae-positive quarter milk samples and on a random sample of MEQ-negative samples $(\mathrm{n}=152)$. Testing all quarters included in the study with Somaticell was not possible because of test availability; thus, a random sample of 152 culturenegative quarters (without any growth on the plate) was selected to exceed the necessary sample size and be of approximately the same size as the sample of positive quarters. Somaticell was performed on refrigerated milk upon arrival to the laboratory, following the manufacturer's instructions. Two milliliters of reagent and milk was mixed in a plastic tube and homogenized for $30 \mathrm{~s}$. The tube was then held upside down for $30 \mathrm{~s}$ to drain the solution, and the final reading (cells/mL) was performed using the tube scale.

\section{Sample Size Calculation}

The sample size was calculated to estimate proportions [sensitivity $(\mathbf{S e})$ and specificity $(\mathbf{S p})]$ with a given precision. Assuming $\alpha=0.05$, expected Se and Sp of 0.9 (McDermott et al., 1982), and a margin of error of \pm 0.05 , at least 100 S. agalactiae-infected quarters and 100 uninfected quarters were required to achieve the proposed objectives (Machin et al., 1997).

\section{Statistical Analysis}

Definitions and Analytical Procedures. Microbiological examination of quarter milk samples was considered an imperfect reference test for diagnosing $S$. agalactiae; that is, its Se and Sp may not be $100 \%$ due to reasons such as the detection limit. A cow was considered positive based on MEQ if S. agalactiae was isolated from $\geq 1$ quarter. When $\geq 1$ quarter milk samples were contaminated and $S$. agalactiae was not isolated from any other quarter, results were considered missing values. Sensitivity, $\mathrm{Sp}$, positive predictive value, and negative predictive value were defined as previously described (Dohoo et al., 2009). Accuracy was defined as the probability of a quarter or cow being correctly classified by a diagnostic test.

To estimate MEC parameters to detect cows infected with S. agalactiae, analyses were performed at the cow level. To estimate accuracy parameters of Somaticell and CMT to detect quarters infected with $S$. agalactiae, and to assess the agreement between the tests, analyses were performed at the quarter level.

Prevalence of S. agalactiae IMI, as well as Se, Sp, proportion of false-negative and false-positive results, positive predictive value, negative predictive value, and accuracy for all tests and thresholds were estimated using Bayesian latent class models. The latent class models used were as follows: 


$$
\begin{gathered}
\mathbf{y}_{\text {observed }} \sim \text { Multinomial }\left(P_{\text {observed }[1: 4]]}, n\right), \\
P_{\text {observed }[1]}=P_{\text {population }} \times\left(S e_{\text {test } 1} \times S e_{\text {test } 2}+\operatorname{cov} D p\right) \\
+\left(1-P_{\text {population }}\right) \times\left[\left(1-S p_{\text {test } 1}\right) \times\left(1-S p_{\text {test } 2}\right)+\operatorname{covDn}\right], \\
P_{\text {observed }[2]}=P_{\text {population }} \times\left[S e_{\text {test } 1} \times\left(1-S e_{\text {test } 2}\right)-\operatorname{covDp}\right] \\
+\left(1-P_{\text {population }}\right) \times\left[\left(1-S p_{\text {test } 1}\right) \times S p_{\text {test } 2}-\operatorname{covDn}\right], \\
+\left[\left(1-P_{\text {population }}\right) \times\left(S p_{\text {test } 1}\right) \times\left(1-S p_{\text {test } 2}\right)-\operatorname{covDn}\right], \\
P_{\text {observed }[3]}=P_{\text {population }} \times\left[\left(1-S e_{\text {test } 1}\right) \times S e_{\text {test } 2}-\operatorname{covDp}\right] \\
+\left(1-P_{\text {population }}\right) \times\left(S p_{\text {test } 1} \times S p_{\text {test } 2}+\operatorname{covDn}\right),
\end{gathered}
$$

and

$$
\operatorname{logit}\left(P_{\text {population }}\right)=(\text { response part })
$$

where $\mathbf{y}_{\text {observed }}$ is a vector that denotes the number of observed results after $n$ trials that fall in each possible combination according to the diagnostic test results, assumed to follow a multinomial distribution with cell probability $P_{\text {observed }} ; P_{\text {population }}$ represents the true population (quarter or cow) prevalence of $S$. agalactiae; $P_{\text {observed }[1]}$ denotes the probability of a sample being classified as $S$. agalactiae positive by both diagnostic tests 1 and $2 ; P_{\text {observed [2] }}$ denotes the probability of a sample being classified as $S$. agalactiae positive by diagnostic test 1 and $S$. agalactiae negative by diagnostic test $2 ; P_{\text {observed }[3]}$ denotes the probability of a sample being classified as $S$. agalactiae negative by diagnostic test 1 and $S$. agalactiae positive by diagnostic test 2 ; and $P_{\text {observed[4] }}$ denotes the probability of a sample being classified as $S$. agalactiae negative by both diagnostic tests 1 and 2. $S e_{\text {test } 1}, S p_{\text {test } 1}, S e_{\text {test } 2}$, and $S p_{\text {test } 2}$ represent the sensitivities and specificities of test 1 and test 2 , respectively. The response part can be used to model the true prevalence of $S$. agalactiae, conditional on cow or herd; $\operatorname{cov} D p$ and $\operatorname{covDn}$ represent the covariance of test results in the $S$. agalactiae-positive and $S$. agalactiae-negative groups, respectively. Accuracy was estimated using the obtained Se and Sp to estimate the probability of correctly identifying a quarter or a cow.

Three sets of response models were fit with different objectives: (1) prevalence estimation of $S$. agalactiae IMI at the quarter level; (2) prevalence estimation of $S$. agalactiae IMI at the cow level and estimation of test accuracy parameters for MEC; and (3) estimation of test accuracy parameters for Somaticell and CMT at different thresholds for quarter milk samples. Previously reported prior information regarding tests' Se and Sp were incorporated into the Bayesian latent class models (Table 1; Dinsmore et al., 1991). For other parameters, for which no prior information was available (e.g., quarter- and cow-level prevalence of S. agalactiae IMI, Se and Sp of Somaticell and CMT, and the covariance between the tests), vague priors were used [e.g., $\beta$ $(1,1)]$. Prior information regarding Se and Sp of MEQ to diagnose $S$. agalactiae IMI was assumed the same at the quarter and cow levels (Table 1). A sensitivity analysis was performed to determine the optimal width of prior distributions to avoid overly specific priors. Posterior distributions obtained under different priors were compared visually.

For all 3 sets of response models, a Markov chain Monte Carlo approach using Gibbs sampling was performed with 4 chains in parallel with a total of 100,000 iterations ( $\mathrm{R}$ runjags package; Denwood, 2016). Visual inspection of the chains, autocorrelation plots, and effective sample sizes were used as measures of efficacy. An effective sample size of at least 10,000 was deemed appropriate for any parameter of interest. Posterior distribution plots were visualized and summary statistics

Table 1. Mode and 95\% credible intervals (CR) of prior distributions used for the different accuracy parameters, by milk sample type and level of analysis

\begin{tabular}{lllrrrr}
\hline \multirow{2}{*}{$\begin{array}{l}\text { Milk sample } \\
\text { type }\end{array}$} & & & & & \multicolumn{2}{c}{$95 \%$ CR } \\
\cline { 5 - 7 } & Level & Parameter & Distribution & Mode & Lower & Upper \\
\hline Quarter & Quarter & Sensitivity & $(44.74,2.00)$ & 0.98 & 0.90 & 0.99 \\
& & Specificity & $(115.90,1.54)$ & 0.99 & 0.96 & 0.99 \\
Quarter & Cow & Sensitivity & $(44.74,2.00)$ & 0.98 & 0.90 & 0.99 \\
& & Specificity & $(115.90,1.54)$ & 0.99 & 0.96 & 0.99 \\
Composite $^{2}$ & Cow & Sensitivity & $(109.70,6.11)$ & 0.96 & 0.90 & 0.99 \\
& & Specificity & $(115.90,1.54)$ & 0.99 & 0.96 & 0.99 \\
\hline
\end{tabular}

${ }^{1}$ Sensitivity to detect a Streptococcus agalactiae IMI; specificity to detect an uninfected quarter or cow.

${ }^{2}$ Mixture of milk from all quarters of a cow. 
(e.g., mode) as well as $95 \%$ credible intervals (CR) were estimated for all parameters of interest.

Prevalence Estimation of S. agalactiae IMI at the Quarter Level. To estimate the prevalence of $S$. agalactiae at the quarter level, mixed-effects logistic regression models were fit with herd and cow as random effects, to account for the correlation between quarters within the same cow, as follows:

$$
\operatorname{logit}\left(P_{i j k} \mid b_{k} b_{j k}\right)=\beta_{0} \text { cons }+b_{k}+b_{j k},
$$

where $P_{i j k}$ represented the probability of quarter $i$ in cow $j$ and herd $k$ having a $S$. agalactiae IMI; $b_{k}$ are herdspecific random effects and $b_{j k}$ are cow-specific random effects; and $\beta_{0}$ represents the conditional log odds of an $S$. agalactiae IMI. Logit values obtained were converted to population-averaged values (Dohoo et al., 2009), and the inverse logit function was used for presentation of prevalence estimates. Models were fit using only results from MEQ because the Somaticell was not performed on all quarters; hence, no Se and Sp for Somaticell, as well as covariance parameters, were present in this model.

Prevalence Estimation of $S$. agalactiae IMI at the Cow Level and Estimation of MEC Accuracy Parameters. To estimate the prevalence of $S$. agalactiae at the cow level and MEC parameters, mixed-effects logistic regression models were fit with herd as a random effect. Analyses were based on microbiological examination of both quarter and composite milk samples, accounting for the covariance between the 2 tests (Branscum et al., 2005). Prevalence estimates were converted to population-averaged values (Dohoo et al., 2009), and the inverse logit function was used for presentation.

Estimation of Somaticell and CMT Accuracy Parameters. Different thresholds for each test were evaluated against MEQ (reference test) to detect an $S$. agalactiae IMI at the quarter level. Based on the Somaticell reading scale, 5 thresholds were initially selected: $98,000,147,000,205,000,244,000$, and 282,000 cells $/ \mathrm{mL}$. These thresholds were chosen because they were the closest on the test scale to the 200,000 cells $/ \mathrm{mL}$ threshold, with 50,000 cells/mL intervals from 100,000 to 300,000 cells $/ \mathrm{mL}$. The lowest Somaticell measurable value $(69,000$ cells $/ \mathrm{mL})$ was also used as a threshold. For the CMT, previously reported thresholds of trace, 1, 2, and 3 were used for analysis (Sargeant et al., 2001; Dingwell et al., 2003). Reported mean SCC for CMT scores of trace, 1, 2, and 3 were $386,500,481,462$, $1,633,000$, and 2,328,000 cells/mL, respectively (Amaral and Ruegg, 2005).
For these analyses, observations from the same herd were assumed independent. To estimate CMT parameters, quarters for which Somaticell results were not available were excluded from the analysis to ensure a fair comparison between the tests. Because S. agalactiae shedding and SCC in milk are positively correlated (Lopes et al., 2012), conditional independence was not assumed and the analysis accounted for the covariance between MEQ and Somaticell or CMT. Overlapping of 95\% CR was used to compare Somaticell and CMT's accuracy parameters.

Agreement Between Somaticell and CMT to Detect $S$. agalactiae IMI. The kappa coefficient was estimated with PROC FREQ (SAS version 9.3, SAS Institute Inc., Cary, NC) to assess the agreement between Somaticell and CMT at the thresholds of greatest accuracy. Nonparametric receiver operating characteristic (ROC) curves were constructed for both tests. Microbiological examination of quarter milk samples was considered the reference test for diagnosing a $S$. agalactiae IMI. Comparison between ROC curves was performed by calculating the area under the curve and their respective 95\% CI (PROC LOGISTIC, SAS Institute Inc.). Statistical significance was declared at $P<0.05$.

\section{RESULTS}

Of the 1,164 quarters (304 cows) included in the study, 292, 138, 77, 124, 92, 162, and 279 were from herds $A$ to $G$, respectively. The number of missing values for the reference and index tests is presented in Figure 1. Apparent prevalence of $S$. agalactiae IMI (based on microbiological examination of milk) was $15.8 \%(\mathrm{n}=184 / 1,164)$ at the quarter level and $28.5 \%$ $(\mathrm{n}=83 / 291)$ at the cow level. The true prevalence, as determined by Bayesian models, was 13.0\% (95\% CR: $6.4-24.4 \%)$ at the quarter level, and $25.6 \%$ (95\% CR: $15.3-39.5 \%)$ at the cow level.

\section{Diagnostic Accuracy of Microbiological Examination of Composite Milk Samples (Cow-Level Analysis)}

Sensitivity and Sp of MEC were 95.6\% (95\% CR: 91.1-98.1\%) and 99.5\% (95\% CR: 96.6-100\%; Table 2), respectively. The accuracy of MEC was $98.2 \%$ (Table 2 ) and the agreement between MEC and MEQ was 0.90 (95\% CI: 0.84-0.95; kappa coefficient).

\section{Diagnostic Accuracy of Somaticell and CMT (Quarter-Level Analysis)}

The final data set used for this analysis included 167 S. agalactiae MEQ-positive and a random sample of 152 
MEQ-negative milk samples. Median SCC (Q1 - Q3), as performed with Somaticell, was 1,510,000 (630,000$1,970,000)$ and $98,000(80,000-166,000$ cells $/ \mathrm{mL})$ for $S$. agalactiae-positive $(\mathrm{n}=167)$ and $S$. agalactiae-negative $(\mathrm{n}=152)$ milk samples, respectively. The distribution of CMT scores was as follows: negative $=7.2 \%$, trace $=$ $1.2 \%, 1=1.2 \%, 2=8.4 \%$, and $3=82.0 \%$ for $S$. agalactiae MEQ-positive samples, and negative $=82.2 \%$, trace $=7.9 \%, 1=2.6 \%, 2=1.3 \%$, and $3=5.9 \%$ for MEQ-negative samples.

The Se of Somaticell ranged from 94.9 to $99.5 \%$ to detect $S$. agalactiae IMI (Table 2 and Figure 2), and Sp ranged from 48.1 to $87.1 \%$. At the lowest threshold $(69,000$ cells $/ \mathrm{mL} ; \mathrm{Se}=99.9 \% ; 95 \%$ CR: $98.2-100 \%)$, the Se of Somaticell was higher than that of CMT at any tested threshold. At the lowest threshold, Somati-

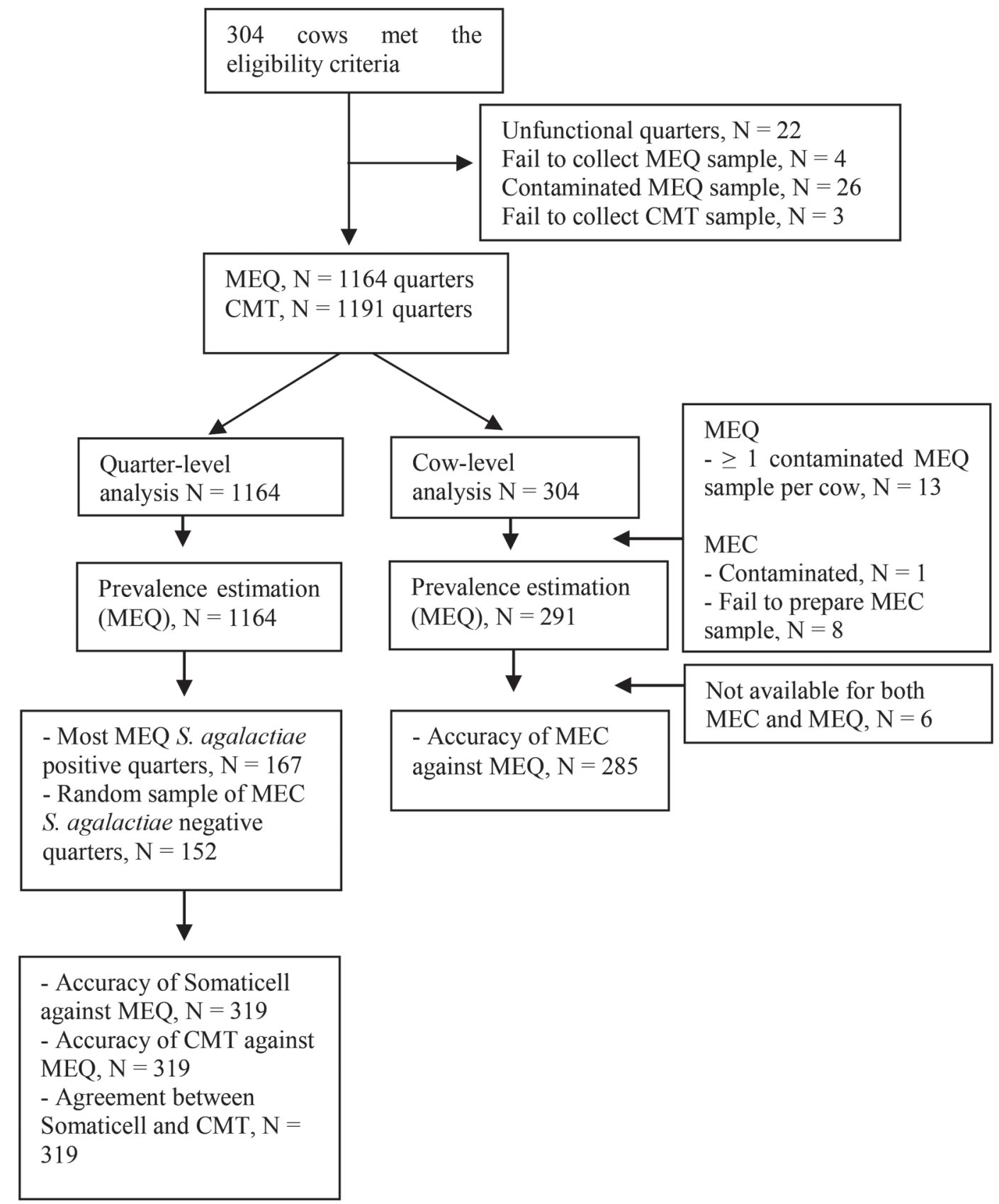

Figure 1. Completeness of the data sets used for prevalence estimation and accuracy of Somaticell (Idexx Laboratories Inc., Westbrook, ME), California Mastitis Test (CMT), and microbiological examination of composite milk (MEC) to identify quarters and cows infected with Streptococcus agalactiae. The reference test was microbiological examination of quarter milk samples (MEQ). 


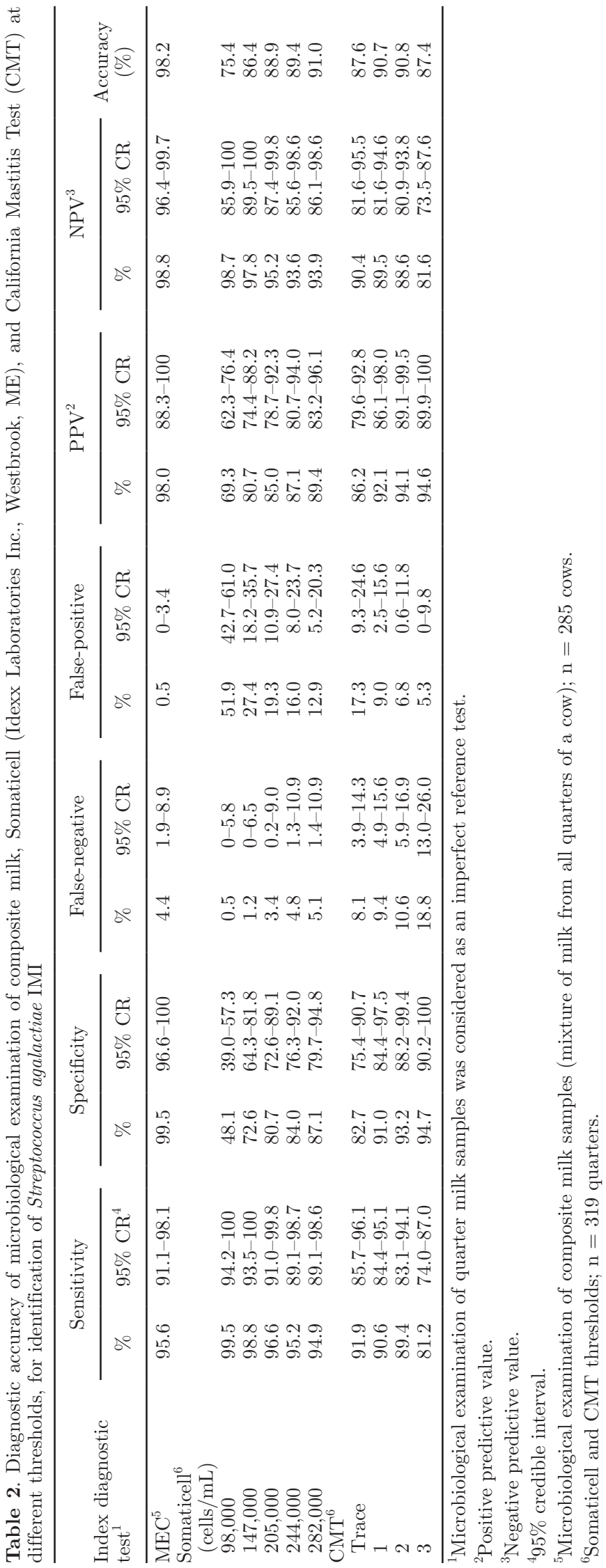

cell would detect all S. agalactiae-infected quarters. The percentage of false-negative results with Somaticell at 69,000 and 98,000 cells $/ \mathrm{mL}$ was lower than that with CMT at thresholds of 2 and 3. Thresholds of 282,000 cells $/ \mathrm{mL}$ (Somaticell) and score 2 (CMT) resulted in the greatest test accuracies (Table 2, Figure 2).

\section{Agreement Between Somaticell and CMT}

At the thresholds of greatest accuracy (Somaticell $=282,000$ cells $/ \mathrm{mL}$ and CMT $=$ score 2$), 157(86.7 \%)$ and $24(13.3 \%)$ of the 181 Somaticell-positive milk samples were considered positive and negative by use of CMT, respectively. Of the 138 Somaticell-negative milk samples, $133(96.4 \%)$ and $5(3.6 \%)$ were considered negative and positive by use of CMT, respectively. The agreement between the tests (kappa coefficient) was 0.82 (95\% CI: 0.76-0.88). The area under the ROC curve for Somaticell and CMT was 94.5\% (95\% CI: 91.8-97.2\%) and 92.0\% (95\% CI: 88.6-95.4\%), respectively $(P=0.09$, Figure 3$)$.

\section{DISCUSSION}

In traditional eradication programs, all quarters of a cow previously diagnosed with $S$. agalactiae by means of MEC have been treated with intramammary antimicrobials, regardless of the number of infected quarters (Erskine and Eberhart, 1990; Reyes et al., 2015). This treatment strategy has become less acceptable because of the increasing pressure to reduce antimicrobial use in livestock animals, and the cost of unnecessarily treating uninfected quarters. In the Netherlands, preventive use of antimicrobials in animals has been prohibited (Speksnijder et al., 2015). Likewise, traditional treatment strategies, such as blanket dry-cow therapy, have been replaced by other alternatives, such as selective dry-cow therapy (Scherpenzeel et al., 2016).

In this context, the results of the present study can be used to reduce the use of antimicrobials in S. agalactiae eradication programs by using SCC-based diagnostic tests to identify infected quarters from cows previously diagnosed with $S$. agalactiae by means of MEC. The Somaticell threshold that resulted in the greatest accuracy to detect $S$. agalactiae IMI was 282,000 cells $/ \mathrm{mL}$, at which Se and Sp were 94.9 and $87.1 \%$, respectively. Nonetheless, the most accurate threshold (at which both Se and Sp are maximized) may not always be the most useful for $S$. agalactiae eradication programs. A substantial effort must be made to maximize the identification of $S$. agalactiae truly infected quarters (Se) because false-negative quarters are left untreated and can be a source of infection to healthy quarters, compromising the eradication program and frustrating 


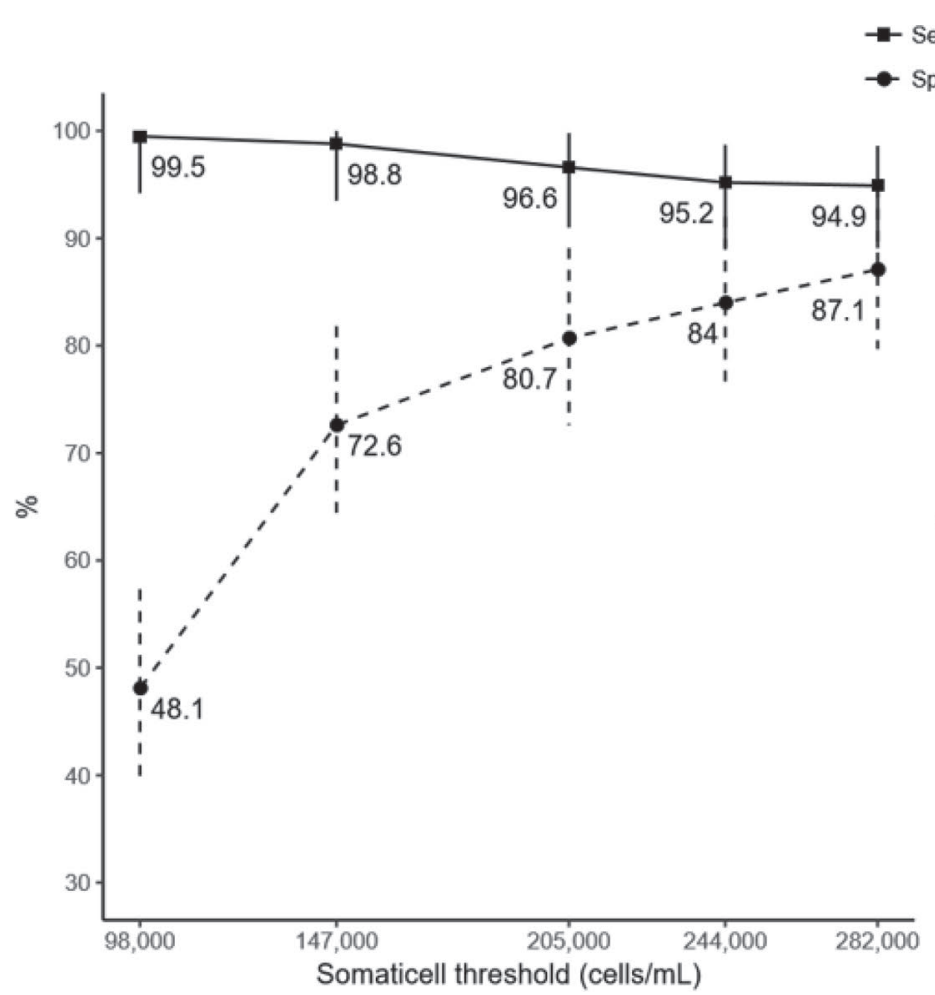

Sensitivity

Specificity

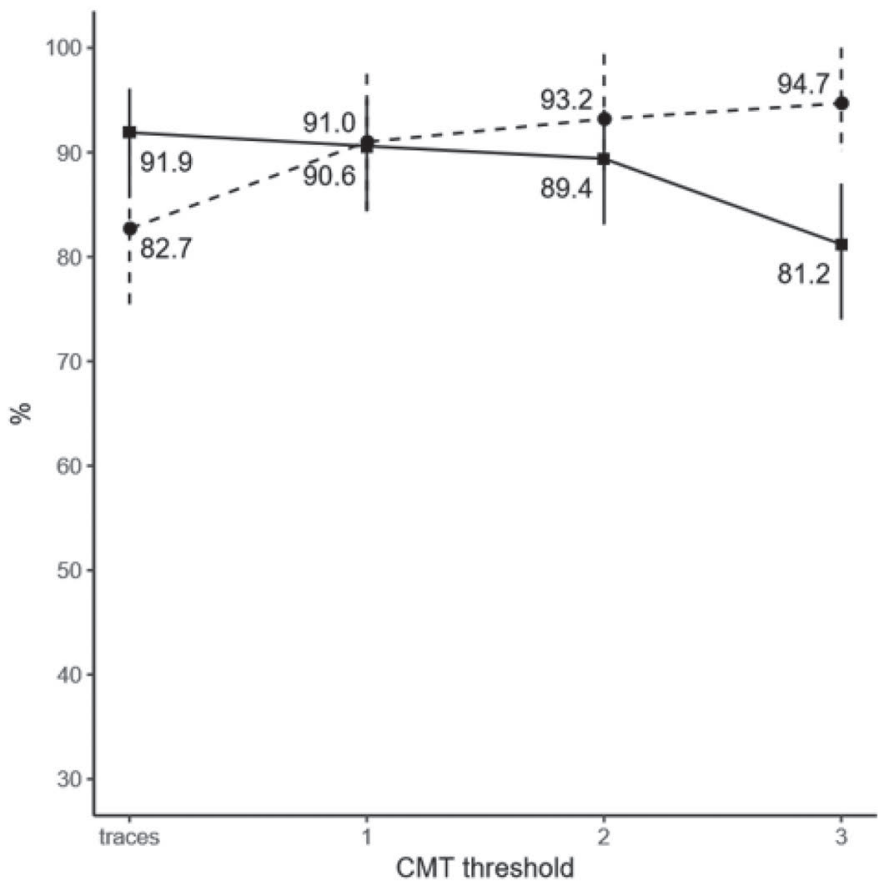

Figure 2. Sensitivity and specificity of Somaticell (Idexx Laboratories Inc., Westbrook, ME; left) and California Mastitis Test (CMT; right) at different thresholds to detect Streptococcus agalactiae IMI ( $=319$ quarter milk samples). The reference test was microbiological examination of quarter milk samples. Vertical bars indicate $95 \%$ credible intervals.

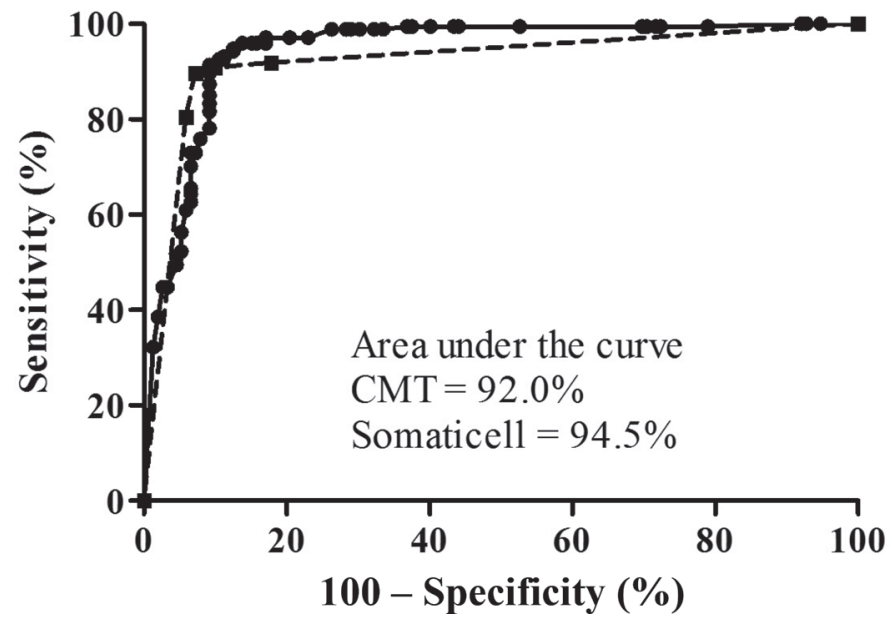

Figure 3. Receiver operating characteristic nonparametric curves to assess the accuracy of Somaticell (Idexx Laboratories Inc., Westbrook, ME; -) and California Mastitis Test (CMT; ---) to detect Streptococcus agalactiae IMI ( $\mathrm{n}=319$ quarter milk samples). Thresholds were chosen based on the Somaticell scale $(\bullet)$ and on the CMT scores (ם) of 0 (negative), trace (slight reaction), 1 (mild reaction), 2 (moderate reaction), and 3 (strong reaction). Microbiological examination of quarter milk samples was used as the reference test. the milk producer. Leelahapongsathon et al. (2016) reported that the incidence rate of $S$. agalactiae was 0.09 new cases/quarter-month at risk, suggesting that, in the presence of infected cows, $9 \%$ of healthy quarters would develop new $S$. agalactiae IMI within a 30-d interval. In contrast, false-positive results would lead to unnecessary treatment of uninfected quarters, which would increase therapy costs and the risk of antimicrobial residues in bulk tank milk.

Therefore, threshold changes can be made according to the goals of the eradication program. For example, reducing the Somaticell threshold to 205,000 cells $/ \mathrm{mL}$ would result in only $3.4 \%$ false-negative and $19.3 \%$ falsepositive results; that is, of 100 truly infected quarters, 3 would be misdiagnosed as uninfected and 19 would be unnecessarily treated with an antimicrobial. Reducing the threshold would maximize the identification of truly infected quarters and probably shorten the duration of the eradication program, at the cost of increasing the number of unnecessarily treated quarters. Decreasing the Somaticell threshold from 205,000 to 98,000 cells/ $\mathrm{mL}$ would result in a gain of only 2.9 percentage points in Se (96.6 to $99.5 \%)$ and a loss of 32.6 percentage points in $\mathrm{Sp}$, resulting in unnecessary treatments for $52 \%$ of the uninfected quarters. In contrast, increas- 
ing the threshold would reduce the number of treated quarters, at the cost of increasing the number of falsenegative results. Consultants and dairy producers can use the results of this study to reach their specific goals in $S$. agalactiae eradication programs.

The most accurate CMT threshold was 2 (accuracy $=90.8 \%$ ). Reducing the threshold to trace could facilitate the reading of the test because any viscosity change would be considered a positive result; however, there would be little increase in Se $(89.4$ to $91.9 \%)$ at the cost of increasing the percentage of false-positive results from 6.8 to $17.3 \%$.

Although the areas under the ROC curves were not statistically different, in general Somaticell resulted in higher Se and lower percentages of false-negative results, compared with the lowest threshold (trace) of CMT, which could justify its use in $S$. agalactiae eradication programs.

Microbiological examination of composite milk has traditionally been used as a screening strategy in $S$. agalactiae eradication programs (Reyes et al., 2015). This approach is feasible because of the substantial shedding of bacteria in milk of $S$. agalactiae-infected cows $\left(10^{7}\right.$ bacteria/mL; Guterbock and Blackmer, 1984). The Se and Sp of MEC observed here were slightly lower ( $\mathrm{Se}=$ 95.6 and $\mathrm{Sp}=99.5 \%$ ) than those reported by Dinsmore et al. (1991; $\mathrm{Se}=96.5 \%$ and $\mathrm{Sp}=100 \%)$, perhaps due to a smaller milk volume $(10 \mu \mathrm{L})$ plated on a smaller area (a quarter of a blood-agar plate). Even so, approximately 9 out of 10 truly infected cows would be correctly identified. High Se and low cost are important characteristics of diagnostic tests used for population screening (Dohoo et al., 2009). In S. agalactiae eradication programs, replacement of MEQ by MEC as a screening method would be justifiable because herd screening costs would be reduced to approximately a quarter, with little loss in Se. Reducing costs to identify positive cows might encourage producers to participate in such programs.

One limitation of this study was the use of a random sample of $S$. agalactiae-negative quarter milk samples for assessment of Somaticell and CMT test accuracy. Performing the Somaticell on all negative samples was not possible due to test availability and study logistics. Somaticell was performed using refrigerated milk to simulate farm conditions, which made it very difficult to test a large number of samples after arrival from the farms (farms were distant from the university), in addition to preparing and processing all quarter and composite milk samples. Using all negative samples would allow estimation of predicted values at the actual prevalence observed in the population studied. Nonetheless, we chose to use a sample of MEQ-negative samples of approximately the same size as the sample of MEQ-positive samples, to reproduce a prevalence of S. agalactiae IMI of $50 \%$, which is commonly observed in the regions studied.

\section{CONCLUSIONS}

Microbiological examination of composite milk was an accurate test to identify cows with $S$. agalactiae IMI, detecting $95.6 \%$ of all infected cows. Test accuracy did not differ between Somaticell and CMT. Although the most accurate thresholds for Somaticell and CMT to detect $S$. agalactiae IMI were 282,000 cells $/ \mathrm{mL}$ and score 2, respectively, using lower thresholds may be preferable to maximize Se and minimize the number of false-negative results. In general, Somaticell was more sensitive than CMT to detect $S$. agalactiae IMI, which would decrease the risk of leaving infected quarters in the herd. Consultants and dairy producers could use the results of this study to reduce the use of antimicrobials and reach their specific objectives in $S$. agalactiae eradication programs. Further studies with an economic focus will be important to determine which diagnostic strategy has the best cost-benefit for identifying animals and quarters infected with $S$. agalactiae.

\section{ACKNOWLEDGMENTS}

We thank the farmers and their staff for cooperating with the study. This research was funded by the Sao Paulo Research Foundation (FAPESP; grant 2015/21157-0). The scholarship (132538-2015-6) of R. S. Rossi was provided by the National Council for Scientific and Technological Development (CNPQ, Brasilia, Brazil).

\section{REFERENCES}

Amaral, T., and P. Ruegg. 2005. Association between results of PortaSCC, the CMT and isolation of mastitis pathogens. Pages 289290 in Proc. Natl. Mastitis Counc. Ann. Mtg., Orlando, FL. Natl. Mastitis Counc. Inc., Madison, WI.

Bossuyt, P. M., J. B. Reitsma, D. E. Bruns, C. A. Gatsonis, P. P. Glasziou, L. Irwig, J. G. Lijmer, D. Moher, D. Rennie, H. C. W. de Vet, H. Y. Kressel, N. Rifai, R. M. Golub, D. G. Altman, L. Hooft, D. A. Korevaar, and J. F. Cohen. 2015. STARD 2015: An updated list of essential items for reporting diagnostic accuracy studies. BMJ 351:h5527. https://doi.org/10.1136/bmj.h5527.

Branscum, A. J., I. A. Gardner, and W. O. Johnson. 2005. Estimation of diagnostic-test sensitivity and specificity through Bayesian modeling. Prev. Vet. Med. 68:145-163. https://doi.org/10.1016/j .prevetmed.2004.12.005.

Brito, M. A. V. P., J. R. F. Brito, M. T. Ribeiro, and V. M. O. Veiga. 1999. Padrão de infecção intramamária em rebanhos leiteiros: Exame de todos os quartos mamários das vacas em lactação. Arq. Bras. Med. Vet. Zootec. 51:129-135. https://doi.org/10.1590/ S0102-09351999000200001.

Chen, M., L. Li-Ping, R. Wang, W. Liang, Y. Huang, J. Li, A. Lei, W. Huang, and X. Gan. 2012. PCR detection and PFGE genotype analyses of streptococcal clinical isolates from tilapia in China. 
Vet. Microbiol. 159:526-530. https://doi.org/10.1016/j.vetmic .2012.04.035.

Denwood, M. J. 2016. Runjags: An R package providing interface utilities, model templates, parallel computing methods and additional distributions for MCMC models in JAGS. J. Stat. Softw. 71:1-25. https://doi.org/10.18637/jss.v075.i01.

Dingwell, R. T., K. E. Leslie, Y. H. Schukken, J. M. Sargeant, and L. L. Timms. 2003. Evaluation of the California Mastitis Test to detect an intramammary infection with a major pathogen in early lactation dairy cows. Can. Vet. J. 44:413-415.

Dinsmore, R. P., P. B. English, R. N. Gonzalez, and P. M. Sears. 1992. Use of augmented cultural techniques in the diagnosis of the bacterial cause of clinical bovine mastitis. J. Dairy Sci. 75:2706-2712. https://doi.org/10.3168/jds.S0022-0302(92)78032-1.

Dinsmore, R. P., P. B. English, R. N. Gonzalez, P. M. Sears, and H. F. Schulte. 1991. Evaluation of methods for the diagnosis of Streptococcus agalactiae intramammary infections in dairy cattle. J. Dairy Sci. 74:1521-1526. https://doi.org/10.3168/jds.S0022 $-0302(91) 78312-4$.

Djabri, B., N. Bareille, F. Beaudeau, and H. Seegers. 2002. Quarter milk somatic cell count in infected dairy cows: A meta-analysis. Vet. Res. 33:335-357.

Dohoo, I., S. W. Martin, and H. Stryhn. 2009. Veterinary Epidemiologic Research. 2nd ed. VER Inc., Charlottetown, PEI, Canada.

Erskine, R. J., and R. J. Eberhart. 1990. Herd benefit-to-cost ratio and effects of a bovine mastitis control program that includes blitz treatment of Streptococcus agalactiae. J. Am. Vet. Med. Assoc. 196:1230-1235.

European Medicines Agency. 2014. Answers to the requests for scientific advice on the impact on public health and animal health of the use of antibiotics in animals. EMA/381884/2014. European Medicines Agency, London, UK.

Guterbock, W. M., and P. E. Blackmer. 1984. Veterinary interpretation of bulk tank milk. Vet. Clin. North Am. Large Anim. Pract. 6:257-268. https://doi.org/10.1016/S0196-9846(17)30021-6.

Hogan, J. S., J. W. Pankey, P. Murdough, and D. B. Howard. 1986 Survey of bulk tank milk using blood-esculin agar counts. J. Food Prot. 49:990-993. https://doi.org/10.4315/0362-028X-49.12.990.

Katholm, J., T. W. Bennedsgaard, M. T. Koskinen, and E. Rattenborg. 2012. Quality of bulk tank milk samples from Danish dairy herds based on real-time polymerase chain reaction identification of mastitis pathogens. J. Dairy Sci. 95:5702-5708. https://doi.org/ $10.3168 /$ jds.2011-5307.

Keefe, G. P. 1997. Streptococcus agalactiae mastitis: A review. Can. Vet. J. 38:429-437.

Leelahapongsathon, K., Y. H. Schukken, T. Pinyopummintr, and W. Suriyasathaporn. 2016. Comparison of transmission dynamics between Streptococcus uberis and Streptococcus agalactiae intramammary infections. J. Dairy Sci. 99:1418-1426. https://doi.org/10 $.3168 /$ jds.2015-9950.

Leelahapongsathon, K., Y. H. Schukken, and W. Suriyasathaporn. 2014. Quarter, cow, and farm risk factors for intramammary infections with major pathogens relative to minor pathogens in Thai dairy cows. Trop. Anim. Health Prod. 46:1067-1078. https://doi .org/10.1007/s11250-014-0603-8.

Lopes, J. E. F., C. C. Lange, M. A. V. P. Brito, F. R. Santos, M. A. S. Silva, L. C. D. de Moraes, and G. N. de Souza. 2012. Relationship between total bacteria counts and somatic cell counts from mammary quarters infected by mastitis pathogens. Cienc. Rural 42:691-696.

Machin, D., M. Campbell, P. Fayers, and A. Pinol. 1997. Sample Size Tables for Clinical Studies. 2nd ed. Wiley-Blackwell Science, Oxford, UK.

Markey, B., F. Leonard, M. Archambault, A. Cullinane, and D. Maguire. 2013. The streptococci and related cocci. Pages 121-134 in Clinical Veterinary Microbiology. 2nd ed. Elsevier, Edinburgh, UK.

McDermott, M. P., H. N. Erb, and R. P. Natzke. 1982. Predictability by somatic cell counts related to prevalence of intrammary infection within herds. J. Dairy Sci. 65:1535-1539. https://doi.org/10 .3168/jds.S0022-0302(82)82378-3.

National Mastitis Council. 1999. Laboratory Handbook on Bovine Mastitis. National Mastitis Council, Verona, WI.

Natzke, R. P., R. W. Everett, R. S. Guthrie, J. F. Keown, A. M. Meek, W. G. Merrill, S. J. Roberts, and G. H. Schmidt. 1972. Mastitis control program: Effect on milk production. J. Dairy Sci. 55:12561260. https://doi.org/10.3168/jds.S0022-0302(72)85658-3.

Ramírez, N. F., G. Keefe, I. Dohoo, J. Sánchez, O. Arroyave, J. Cerón, M. Jaramillo, and L. G. Palacio. 2014. Herd- and cow-level risk factors associated with subclinical mastitis in dairy farms from the high plains of the northern Antioquia, Colombia. J. Dairy Sci. 97:4141-4150. https://doi.org/10.3168/jds.2013-6815.

Reyes, J., M. Chaffer, J. Sanchez, G. Torres, D. Macias, M. Jaramillo, and G. P. Keefe. 2015. Evaluation of the efficacy of intramuscular versus intramammary treatment of subclinical Streptococcus agalactiae mastitis in dairy cows in Colombia. J. Dairy Sci. 98:52945303. https://doi.org/10.3168/jds.2014-9199.

Rodrigues, A. C. O., L. D. Cassoli, P. F. Machado, and P. L. Ruegg 2009. Short communication: Evaluation of an on-farm test to estimate somatic cell count. J. Dairy Sci. 92:990-995. https://doi.org/ $10.3168 /$ jds.2008-1216.

Sargeant, J. M., K. E. Leslie, J. E. Shirley, B. J. Pulkrabek, and G. H. Lim. 2001. Sensitivity and specificity of somatic cell count and California Mastitis Test for identifying intramammary infection in early lactation. 2001. J. Dairy Sci. 84:2018-2024.

Scherpenzeel, C. G. M., I. E. M. den Uijl, G. van Schaik, R. O. Riekerink, H. Hogeveen, and T. J. G. M. Lam. 2016. Effect of different scenarios for selective dry-cow therapy on udder health, antimicrobial usage, and economics. J. Dairy Sci. 99:3753-3764. https://doi .org/10.3168/jds.2015-9963.

Speksnijder, D. C., D. J. Mevius, C. J. M. Bruschke, and J. A. Wagenaar. 2015. Reduction of veterinary antimicrobial use in the Netherlands. The Dutch success model. Zoonoses Public Health 62:79-87. https://doi.org/10.1111/zph.12167.

Thompson, D. I., and D. S. Postle. 1964. The Wisconsin Mastitis Test-An indirect estimation of leucocytes in milk. J. Milk Food Technol. 27:271-275.

Wilson, D. J., R. N. Gonzalez, and H. das Helena. 1997. Bovine mastitis pathogens in New York and Pennsylvania: Prevalence and effects on somatic cell count and milk production. J. Dairy Sci. 80:2592-2598. https://doi.org/10.3168/jds.S0022-0302(97)76215 $-5$.

Yang, Y., Y. Liu, Y. Ding, L. Yi, Z. Ma, H. Fan, and C. Lu. 2013. Molecular characterization of Streptococcus agalactiae isolated from bovine mastitis in eastern China. PLoS One 8:e67755. https://doi .org/10.1371/journal.pone.0067755. 